\title{
BMJ Open Evaluation of the district health management fellowship training programme: a case study in Iran
}

\author{
Kamal Gholipour, ${ }^{1,2,3}$ Jafar Sadegh Tabrizi, ${ }^{1,2}$ Mostafa Farahbakhsh, ${ }^{4}$ \\ Shabnam lezadi, ${ }^{3}$ Akbar Ghiasi, ${ }^{5}$ Hasan Jahanbin ${ }^{6}$
}

To cite: Gholipour K, Tabrizi JS, Farahbakhsh M, et al. Evaluation of the district health management fellowship training programme: a case study in Iran. BMJ Open 2018;8:e020603. doi:10.1136/ bmjopen-2017-020603

- Prepublication history for this paper is available online. To view these files, please visit the journal online (http://dx.doi. org/10.1136/bmjopen-2017020603).

Received 13 November 2017 Revised 9 January 2018 Accepted 26 January 2018

Check for updates

For numbered affiliations see end of article.

Correspondence to Dr Shabnam lezadi; iezadish@tbzmed.ac.ir

\section{ABSTRACT}

Objective To evaluate the district health management fellowship training programme in the north-west of Iran. Data sources/study setting The programme was introduced to build the managerial capacity of district health managers in Iran. Eighty-nine heads of units in the province's health centre, district health managers and the health deputies of the district health centres in the northwest provinces of Iran had registered for the district health management fellowship training programme in Tabriz in 2015-2016.

Study design This was an educational evaluation study to evaluate training courses to measure participants' reactions and learning and, to a lesser extent, application of training to their job and the organisational impact. Data collection/extraction methods Valid and reliable questionnaires were used to assess learning techniques and views towards the fellowship, and self-assessment of health managers' knowledge and skills. Also, pretest and post-test examinations were conducted in each course and a portfolio was provided to the trainees to be completed in their work settings.

Principal findings About $63 \%$ of the participants were medical doctors and $42.3 \%$ of them had over 20 years of experience. Learning by practice (scored 18.37 out of 20) and access to publications (17.27) were the most useful methods of training in health planning and management from the participants' perspective. Moreover, meeting peers from other districts and the academic credibility of teachers were the most important features of the current programme. Based on the managers' self-assessment, they were most skilful in quality improvement, managing, planning and evaluation of the district. The results of the post-test analysis on data collected from district health managers showed the highest scores in managing the district (77 out of 100) and planning and evaluation (69) of the courses.

Conclusion The results of this study indicated that training courses, methods and improvement in managers' knowledge about the health system and the skills necessary to manage their organisation were acceptable.

\section{INTRODUCTION}

A health system is an arrangement of the organisational structure, physical resources and staff to improve the health status of a particular population. In the last

\section{Strengths and limitations of this study}

- Use if short-term and more subjective measures, pre-test and post-test rather than the real impact of the programme is a limitation.

- The high managerial turnover rate makes it impossible to follow-up the impact of the programme.

- We did not analyse the role of other factors and confounders.

- The programme developed was used by the Ministry of Health as an applicable package for training district health managers across the country.

- The training content was considered as applicable, useful and relevant to real work settings.

decades, strengthening the health system and its infrastructure has become as one of the priorities in progressive health systems, especially in developing countries. ${ }^{1}$

Strengthening of the leadership and management in a health system is one of the most challenging issues that need to be measured and there are few empirical studies of its impact on service delivery and health outcomes. ${ }^{23}$ In addition, the existing literature in developing countries indicates shortfalls in managerial capabilities and training programmes. For example, Muchekeza et al conducted a study in Zimbabwe and concluded that almost half of the district health managers do not list the tasks of district health executives and some of them had insufficient managerial skills and training. ${ }^{4}$ Also, financing, health policy and health management were perceived to be the most essential requirements of management training in Kenya, Nigeria and Senegal. ${ }^{5}$ Bonenberger et al demonstrated that data management, attending workshops, travelling, financial management, training of staff, and drugs and supply management were the highest time-consuming tasks of district health managers in Ghana. ${ }^{6}$ Furthermore, Asante $e t$ al recognised that lack of skills in 
Table 1 Training courses of district management training fellowships

\begin{tabular}{llll}
\hline Educational courses & Summary of content & Location* & $\begin{array}{l}\text { Date } \\
\text { (duration) }\end{array}$ \\
\hline Management, leadership & $\begin{array}{l}\text { Basic concepts of management, leadership and supervision, } \\
\text { change management, team management, conflict } \\
\text { management, basic skills in communication, staff motivation }\end{array}$ & NPMC Tabriz, Iran June 2015 \\
(2 days)
\end{tabular}

*National Public Health Management Centre (NPMC), Maraghe University of Medical Sciences (MUMS), Ardabil University of Medical Sciences (AUMS), Zanjan University of Medical Sciences (ZUMS).

PDCA, plan, do, check, act; PHC, primary health care.

financing and human resource management among provincial health departments in the Solomon Islands was the main concern while management support systems were not able to support managers. ${ }^{7}$

Filerman indicated that the core competencies of health management were human resources management, general management skills and the skills of the top management. ${ }^{8}$ Team-based job training is an effective strategy to improve the effectiveness of management training programmes. ${ }^{8}$ The interventions designed to strengthen leadership and management must lay emphasis on changes in health and service delivery outcomes. However, due to complications in investigating the relationship between managers' empowerment programme with health provision and health status, many researchers have concentrated on managers' knowledge and skills. ${ }^{39}$ According to De Brouwere's and Van Balen's study, most of the trainees applied the skills and knowledge gained from a 12-week training course. Also, team-based district health management, and use of updated and participatory approaches in the training programme could be attributed to the success of the training course. ${ }^{10}$

In Iran, the district health managers of district rural health facilities, district hospitals, health centres, and health posts. Each of these facilities is involved in providing specific health services. District hospitals deliver inpatient and outpatient services. Health centres concentrate on ambulatory and preventive services. Health posts are supposed to be the first line of exposure for patients, providing a large range of preventive and primary services. Also, the provincial health centre department directs district health centres. Like many developing countries, general physicians are appointed as health managers of district and subdistrict centres without any formal or hands-on training. ${ }^{11} 12$

The focus of the newly proposed reforms in the health system, that is supported by the World Bank, is on market mechanisms, effectiveness and efficiency. ${ }^{13}$ Because of 


\begin{tabular}{lcc}
\hline $\begin{array}{l}\text { Table } 2 \\
\text { assessment }\end{array}$ & Demographics of participants in rating educational \\
\hline Variable & Number & $\%$ \\
\hline Sex & & \\
\hline Male & 61 & 84.7 \\
\hline Female & 11 & 15.3 \\
\hline Age, years & & \\
\hline$<40$ & 17 & 25 \\
\hline $40-50$ & 43 & 61.5 \\
\hline$>50$ & 9 & 13.5 \\
\hline Education & & \\
\hline BSc & 14 & 19.4 \\
\hline MSc & 8 & 11.1 \\
\hline MD & 46 & 63.9 \\
\hline PhD & 4 & 5.6 \\
\hline Job position & & \\
\hline Head of unit & 20 & 27.8 \\
\hline Head of district health deputy & 22 & 30.5 \\
\hline District health manager & 30 & 41.7 \\
\hline Years in current job & & \\
\hline$<5$ & 4 & 5.6 \\
\hline $5-10$ & 6 & 8.3 \\
\hline $10-15$ & 12 & 16.7 \\
\hline $15-20$ & 24 & 33.3 \\
\hline$>20$ & 26 & 36.1 \\
\hline & & \\
\hline
\end{tabular}

the managers' capabilities and their influences, especially in the first line, management is one of the key determinants of health system effectiveness. ${ }^{8}$ For instance, Conn et al found that strengthening the health management programme in Gambia led to some improvements in district-level health services especially in team planning and coordination, and management of the available but limited resources. ${ }^{14}$ Besides, Pfeffermann determined that strengthening the health management programmes was the most cost-effective intervention. ${ }^{15}$

This study aimed to evaluate the district health management fellowship training programme using Kirkpatrick's four-level model (reaction, learning, application and impact $)^{16}$ in the north-west of Iran. The programme was designed to build managerial capability in Iranian district health managers.

\section{MATERIALS AND METHODS \\ Design and setting}

This study, based on Kirkpatrick's framework, was an evaluation of training programmes to measure participants' reactions, learning and, to a lesser extent, application of training in their careers, on the basis of the respondents' perception to apply the lessons and the organisational impact. It was conducted between June 2015 and February 2016 in Tabriz.

\section{Participants and the training programme}

Following assessment of the the educational needs proposed by the Ministry of Health, Treatment and Medical Education, a training programme was developed and introduced for district health system managers in the National Public Health Management Centre (NPMC) of the Tabriz University of Medical Sciences, in order to improve their skills and knowledge on health system management. ${ }^{17}$ Eighty-nine health managers registered for this training programme. Two cohorts of 89 health officials (44 and 45 participants in each cohort) were selected by the Ministry of Health, Treatment and Medical Education to participate in the courses (table 1). Our target population was all heads of provincial health centres, district health managers and health deputies of district health centres in the northwest provinces of Iran.

\section{Data collection and instrument}

A valid and reliable questionnaire was used to collect data from participants. We used a questionnaire that was designed in the University of Leeds and had previously been adapted and tested by the NPMC staff and was used as an applicable tool to elucidate management training courses in NPMC. ${ }^{18}$ The questionnaire contained four sections: (1) questions about demographic characteristics of respondents, (2) previous training experiences, the importance of the current training programme and satisfaction from different learning methods in health planning and management among district heath managers, (3) health managers' perceptions about usefulness and applicability of training programmes (4) self-assessment of health managers' knowledge, skills and relevance to their job and future training topics. Totally, 72 of the 89 training participants (response rate $=81 \%$ ) filled up and returned the questionnaire (table 2).

The satisfaction on the different learning methods was rated based on a 4-point Likert Scale (very high, high, moderate, low) and the experiences of the different learning methods were dichotomous variables. Also, the importance of each method was rated on a 0-20 scale. These questionnaires were presented to participants at the beginning of the first course of the training programme.

For assessment of the usefulness and perception of the respondents to apply the lessons learnt from the training material used, the respondents were asked to indicate their agreement to 15 statements (due to negative meaning of some items, sometimes very high had a negative effect on score) on a 5-point Likert Scale. Finally, the results were presented on a 3-point scale as: agree, neutral and disagree.

Self-assessment of the health managers' knowledge and skills was rated on a 4-point scale, and relevance of the courses to their work and future training were rated on a 3-point scale and dichotomous yes or no answers. 
Table 3 Experiences, importance of and satisfaction with learning techniques on health planning, and management among district heath managers

\begin{tabular}{|c|c|c|c|c|c|c|}
\hline Learning method & $\begin{array}{l}\text { Importance } \\
\text { of learning } \\
\text { techniques* }\end{array}$ & $\begin{array}{l}\text { Having } \\
\text { experience } \\
\text { in learning } \\
\text { methods } † \\
\text { Number }(\%)\end{array}$ & \multicolumn{4}{|c|}{$\begin{array}{l}\text { Satisfaction with learning techniques } \\
\text { Number (\%) }\end{array}$} \\
\hline Learning by practice & $18.37(2.1)$ & 59 (81.9) & $29(41.4)$ & $33(47.1)$ & $8(11.4)$ & \\
\hline Working with experienced persons & $13.12(4.9)$ & $53(73.6)$ & $26(37.7)$ & $37(53.6)$ & $5(7.2)$ & $1(1.4)$ \\
\hline Practice or being involved in research & $14.75(3.7)$ & $33(45.8)$ & $7(12.5)$ & $18(32.1)$ & $26(46.4)$ & $5(8.9)$ \\
\hline On-line learning & $13.07(4.6)$ & $28(38.9)$ & $5(9.4)$ & $17(32.1)$ & $23(43.4)$ & $8(15.1)$ \\
\hline Study tours & $15.53(3.4)$ & $19(26.4)$ & $9(22.0)$ & $12(29.3)$ & $8(19.5)$ & $12(29.3)$ \\
\hline Formal certified training & $12.90(5.3)$ & $47(65.3)$ & $9(15.0)$ & $29(48.3)$ & $16(26.7)$ & $6(10.0)$ \\
\hline Attending workshops, meetings and conferences & $14.99(3.9)$ & $51(70.8)$ & $16(24.2)$ & $32(48.5)$ & $17(25.8)$ & $1(1.5)$ \\
\hline Twinning of organisations & $12.78(4.7)$ & $35(48.6)$ & $8(13.8)$ & $20(34.5)$ & $23(39.7)$ & $7(12.1)$ \\
\hline
\end{tabular}

*The importance of each method was rated on a 0-20 scale.

†Number of participants who have declared having experience in that learning method.

Furthermore, pretest and post-test examinations in each course were conducted to evaluate the usefulness of courses in terms of contents. Pretests were performed at the beginning of each course. Simultaneously the posttest related to the previous course was performed. At the beginning of each course, the course directors developed an exam sheet based on the contents of the course. Also, to ensure reliability in assessment only matching, restricted response and multiple choice questions were prepared. A portfolio based on fellowship content was also provided to the trainees to be completed in their work settings.

\section{Ethical considerations}

All participants provided written, signed informed consent before enrolling for the study and filling up the questionnaire. Participants who were not interested in contributing or who did not continue the research process were excluded from the study.

\section{Questionnaire analysis}

Descriptive statistics (mean, SD and frequencies (\%)) were used to point out the basic properties of variables for quantitative and categorical variables. Also, pretest and post-test examinations correcting based on standard response and then normalised as 0 to 100 . For statistical relationship analysis the SPSS V.17 statistical package (SPSS, Chicago, Illinois, USA) was used.

\section{RESULT}

According to the findings, $84.7 \%$ of participants were male, $61.5 \%$ were between 40 years and 50 years of age, $41.7 \%$ were district health managers and $27.8 \%$ were heads of units in provincial health centres. About $63.9 \%$ of the participants were medical doctors. Only $5.6 \%$ of participants had worked 5 years or less in their current position and $36.1 \%$ of them had more than 20 years work experience (table 2 ).

\section{Learning for health planning and management}

Respondents were asked to choose from a range of 0-20 points on 13 learning methods, assigning higher points to the more important methods. Learning by practice (scored 18.37 out of 20), access to publications (17.27), and workshops, meetings and conferences (14.99) were chosen as the three most important methods (table 3).

Also, the trainees indicated that learning by practice $(81.9 \%)$, working with experienced persons $(73.6 \%)$, discussions with colleagues during workshops $(72.2 \%)$, and meetings and conferences $(70.8 \%)$ were the postexperience learning methods among health managers (table 3).

With regard to satisfaction level, respondents determined learning by practice, working with experienced persons, discussions with colleagues, working with colleagues who shared training and workshops, meetings and conferences, as the highest influential factors. Also, on-line learning and practice or being involved in research were reported as the most unsatisfactory methods to training planning and management (table 3).

\section{Overall views on the training courses}

Trainees agreed most strongly with the statements that 'the strength of the course was to make an opportunity to meet up with peers from other districts to share experiences' 
Table 4 Health manager views towards the district management training fellowship courses

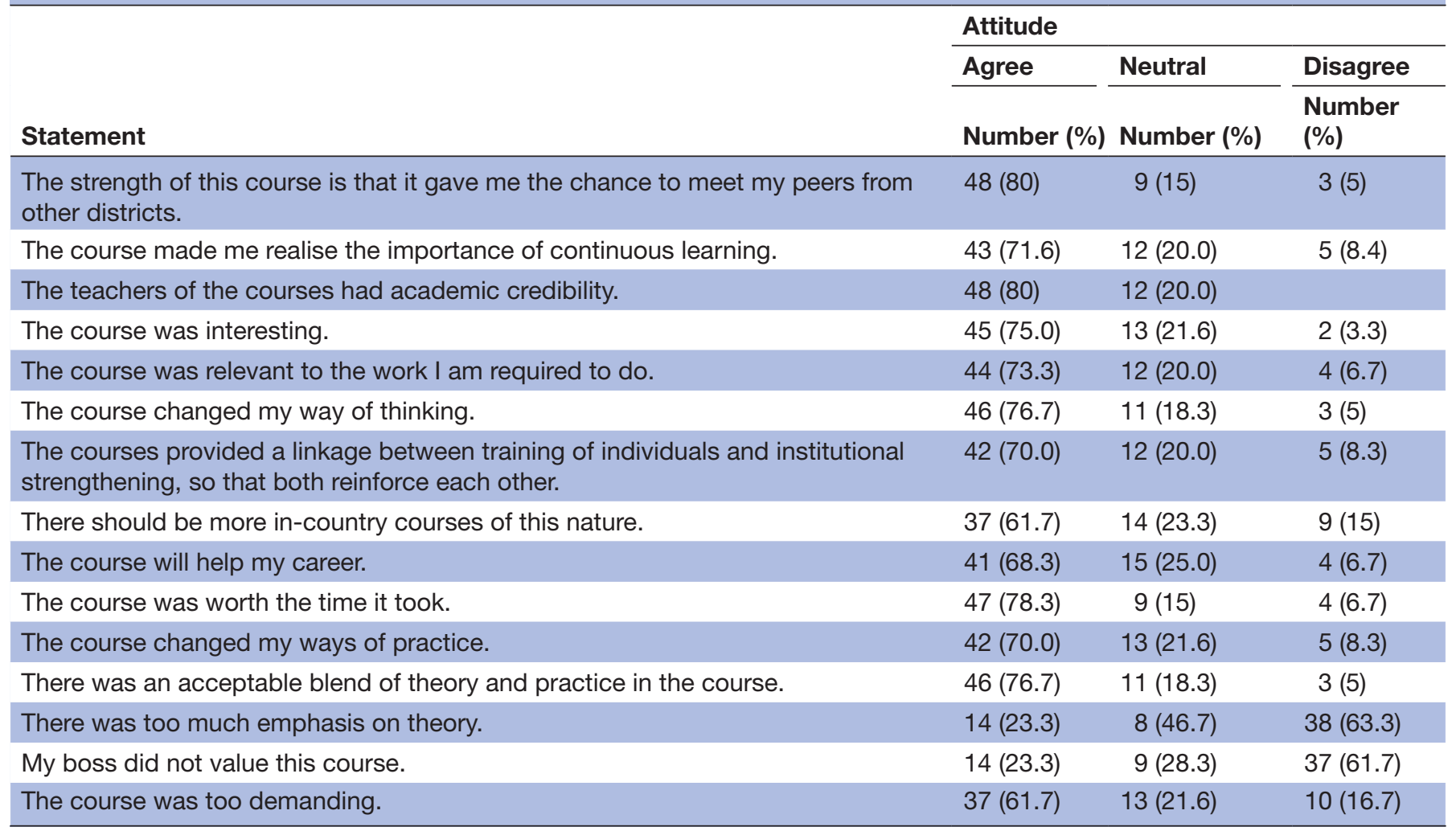

and also "the instructors of the courses had academic credibility'. More than $78 \%$ were satisfied with the amount of time they had spent to attend the training course and more than $76 \%$ mentioned that the mix of theory and practice during the training period was acceptable and that the course had dramatically changed their thoughts. Of the respondents $34 \%$ posited that the course was interesting. More than $60 \%$ of respondents disagreed with the opinion that there was too much emphasis on theory in the courses and their boss did not value these courses (table 4).

\section{Usefulness and respondents' perception on the application of the training lessons}

Based on the findings, most specialised areas of knowledge met the health managers' training needs including quality improvement, managing the district, planning and evaluation, epidemiology and advocacy, and community participation (table 5).

Likewise, participants emphasised that district management, quality improvement, basic management and leadership skills, planning and evaluation, health information management and epidemiology courses were most relevant to their career. On the other hand, accrual accounting and health economics were the least relevance courses (table 5 ).

Also, basic concepts of management and leadership, managing the district, health information management, planning and evaluation, and chronic disease management were the most relevant topics for their future training (table 5).

According to pretest and post-test results, after training, district health managers obtained the highest scores in managing the district (77 out of 100), planning and evaluation (69), chronic disease management (69), human resources and creativity (68), and epidemiology (67). Also, health information (44) and health resources management and health economics (53) gained the least score among health managers. Finally, the courses on managing the district $(51 \%)$, research in the health system (42\%), and human resources and creativity (37\%) had the most positive differences between pretest and post-test scores (figure 1).

\section{DISCUSSION}

This study evaluated the district health management's fellowship training programme in Tabriz based on Kirkpatrick's four-level model. This study was a self-assessment evaluation and a pretest-post-test examination. The results of these analyses indicated that participants' reactions to the training programme were satisfactory and the courses have had a positive effect on attitude, knowledge and skills. Based on respondents' perception the majority of the trainees stated that they would be able to apply the new knowledge and skills to their job. Moreover, due to the positive impact of the training programme, the organisation and process of the district 
Table 5 Self-assessment of health managers' knowledge and skills and respondents' perception to apply the training lessons in each of the fellowship courses

\begin{tabular}{|c|c|c|c|c|c|c|c|c|c|c|}
\hline \multirow[b]{2}{*}{ Topic/subject } & \multicolumn{5}{|c|}{$\begin{array}{l}\text { Level of skills and knowledge } \\
(\%)\end{array}$} & \multicolumn{3}{|c|}{$\begin{array}{l}\text { Relevance to your work } \\
\text { (\%) }\end{array}$} & \multicolumn{2}{|c|}{$\begin{array}{l}\text { Relevance tc } \\
\text { your future } \\
\text { training (\%) }\end{array}$} \\
\hline & 1 & 2 & 3 & 4 & 5 & 1 & 2 & 3 & Yes & No \\
\hline Managing the district & & 6.9 & 36.2 & 41.4 & 15.5 & & 21.4 & 78.6 & 92.5 & 7.5 \\
\hline Quality improvement & 6.9 & 8.6 & 17.2 & 39.7 & 27.6 & 3.6 & 26.8 & 69.6 & 88.2 & 11.8 \\
\hline Health information management & 5.3 & 8.8 & 38.6 & 35.1 & 12.3 & 3.6 & 34.5 & 61.8 & 94.0 & 6.0 \\
\hline Epidemiology & 1.8 & 12.3 & 35.1 & 33.3 & 17.5 & 3.6 & 34.5 & 61.8 & 87.8 & 12.2 \\
\hline Chronic disease management & 3.5 & 21.1 & 38.6 & 24.6 & 12.3 & 9.3 & 38.9 & 51.9 & 92.0 & 8.0 \\
\hline Planning and evaluation & & 12.7 & 32.7 & 32.7 & 21.8 & 1.9 & 31.5 & 66.7 & 91.8 & 8.2 \\
\hline Research in the health system & 5.3 & 14.0 & 33.3 & 26.3 & 21.1 & 10.9 & 34.5 & 54.5 & 85.7 & 14.3 \\
\hline $\begin{array}{l}\text { Advocacy and community } \\
\text { participation }\end{array}$ & 1.7 & 15.5 & 36.2 & 25.9 & 20.7 & 5.4 & 37.5 & 57.1 & 88.0 & 12.0 \\
\hline Accrual accounting & 27.3 & 32.7 & 16.4 & 14.5 & 9.1 & 25.0 & 44.2 & 30.8 & 63.8 & 36.2 \\
\hline Health economics & 19.6 & 30.4 & 26.8 & 16.1 & 7.1 & 24.5 & 35.8 & 39.6 & 75.0 & 25.0 \\
\hline $\begin{array}{l}\text { Human resources and } \\
\text { organisational creativity }\end{array}$ & 5.8 & 28.8 & 25.0 & 25.0 & 15.4 & 15.1 & 32.1 & 52.8 & 82.6 & 17.4 \\
\hline Management, leadership & 1.8 & 25.5 & 29.1 & 29.1 & 14.5 & 5.7 & 26.4 & 67.9 & 95.8 & 4.2 \\
\hline Rules and ethics & 10.9 & 27.3 & 23.6 & 23.6 & 14.5 & 11.3 & 34.0 & 54.7 & 89.1 & 10.9 \\
\hline
\end{tabular}

' 1 ' - no knowledge/skills at all and ' 5 '-comprehensive knowledge and sound practical skills.

Relevance of the particular topic to work on a scale of $1-3$, where ' 1 ' - not relevant and ' 3 ' - completely relevant.

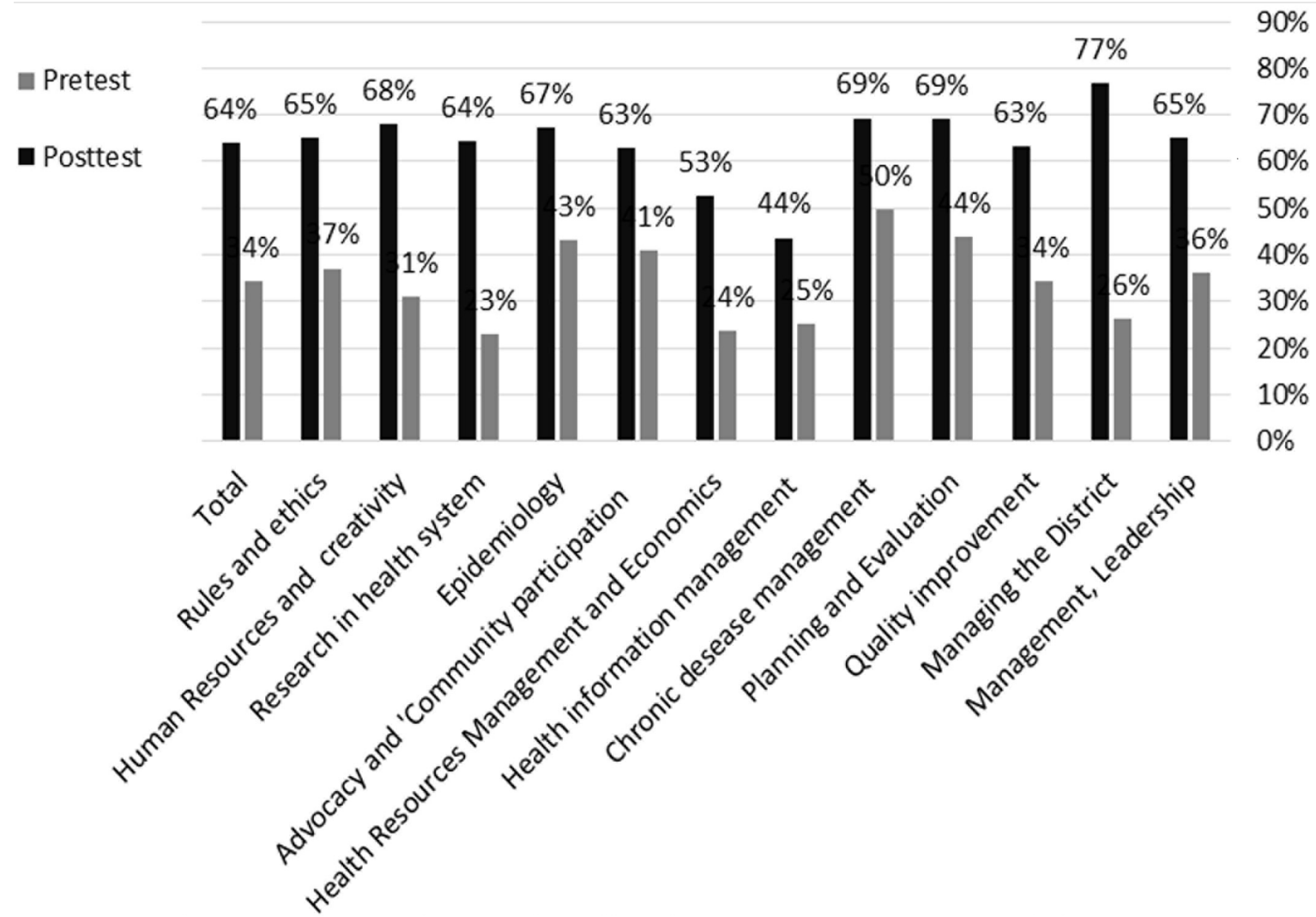

Figure 1 Pretest and post-test results of the district management training fellowships' training courses. 
health system would be improved by trained and empowered managers.

We found that learning by practice, access to publications, workshops, and meetings and conferences were the most useful methods of learning. In addition, learning by practice and working with the experienced were the most satisfactory methods of learning. It is important to note that adult learners can effectively understand teaching content by identifying their training needs, active participation in training programmes and practice what they are learning in their field. ${ }^{19}{ }^{20}$ However, some concerns should be noted in this regard. First, because the district health managers lack formal training in management, ${ }^{11}{ }^{12}$ a formal structured management training in a health setting is essential. ${ }^{21}$ Second, the methods of developing management-related competencies in a real setting may vary given the management levels and different sectors. ${ }^{22-25}$ Third, improving the effectiveness of the management training programme and monitoring the specific system is the most useful way of providing continuous education services for health managers.

Also, based on the results, health managers' satisfaction through on-line training was low. Beanland et al indicated that the use of novel communication technologies such as the internet is an effective training method in the health system. ${ }^{26}$ However, in our study, the low satisfaction with on-line training could be because of a weak on-line learning infrastructure and health system information technology, as well as the low skills of health managers in using these technologies.

According to the findings, meeting peers from other districts in order to share experiences and also academic credibility of the instructors were the most important features of district management training fellowships. Although, many management training programmes are mandatory and they are required by provincial and national authorities in most developing countries, ${ }^{19}$ making the content and structure of training programmes more attractive and useful is an effective strategy for encouraging attendance and increasing the quality of such programmes. For instance, De Brouwere et al found that the supervision, teamworking and problem-solving models are the key elements of successful training courses. ${ }^{27}$ Likewise, Marquez et al revealed that problem-solving training methods can increase the skills and abilities of managers and also produce a new generation of managers for organisations. ${ }^{28}$ However, it must be noted that the policy and practice of governments and donor organisations affect the effectiveness of management capabilities. ${ }^{14}$

Additionally, the results of the study indicated that after the training programme the participants, who were managers with little knowledge of most of the courses, were more skilful in quality improvement, managing the district, and planning and evaluation. In this regard, Muchekeza et al recognised that a lack of management ability of district health executives in Midlands province, Zimbabwe, ${ }^{4}$ and weakness in leadership and priority setting in Uganda were the most perceived shortfalls among district health managers. ${ }^{29}$ Also, leadership and governance,${ }^{29}{ }^{30}$ monitoring and evaluation, human resource management, strategic planning and general health services management, ${ }^{4}$ budgeting and finance, ${ }^{730}$ information management, procurement and supply, ${ }^{729}$ and community participation $^{30}$ were the most required training topics in the different settings.

The results of our study point out that district health managers reached the highest post-test scores in courses of managing the district, planning and evaluation, chronic disease management, human resources, and creativity and epidemiology. Moreover, health information, health resources management and health economics needed more training courses using different teaching methods. We found that the syllabus and teaching methods in this training programme had high and positive effects on improving district health managers' knowledge of managing the district, research in the health system, and human resources and creativity based on the participants' self-assessment. Whereas these findings emerged based on participants' self-assessment and do not be tested in real setting and in the implementation phase, so it's not possible to conclude its effectiveness definitively and practically, however, it can be used as an initial indicator of the effect of educational programme in the real setting. In this regard, Pal et al showed that district health planning, financial management, and technical and administrative issues were the most essential aspects of management training for Madhya Pradesh health managers. ${ }^{31}$ Another study by Conn et al showed that team planning, coordination and resource management were the aspects that could be improved by strengthening health management programmes. ${ }^{14}$ While, Diaz-Monsalve found that continuity of training for health managers and continuous management support were two critical factors for successful and effective education. ${ }^{32}$

\section{CONCLUSION}

The Tabriz health management fellowship training programme was developed based on the educational need assessment of the district health managers in the north-west of Iran and for training them; it was supported by the Ministry of Health, Treatment and Medical education as well as the health deputy of the Tabriz University of Medical Sciences. The results of this study showed an acceptable rate of trainees' satisfaction with the courses and the different teaching methods, and also showed an improvement in their knowledge of health system management. We found that the training contents were applicable, useful and relevant to real work settings. Last but not least, simultaneous and continuous supervision and support is highly beneficial for improving the effectiveness of any training course. 


\section{Author affiliations}

${ }^{1}$ Iranian Center of Excellence in Health Management, Department of Health Services Management, School of Management and Medical Informatics, Tabriz University of Medical Sciences, Tabriz, Iran

${ }^{2}$ Tabriz Health Services Management Research Center, Health Management and Safety Promotion Research Institute, Tabriz University of Medical Sciences, Tabriz, Iran

${ }^{3}$ Social Determinants of Health Research Center, Health Management and Safety Promotion Research Institute, Tabriz University of Medical Sciences, Tabriz, Iran ${ }^{4}$ Road Traffic Injury Research Center, Health Management and Safety Promotion Research Institute, Tabriz University of Medical Sciences, Tabriz, Iran ${ }^{5}$ Department of Health Services Administration, School of Health Professions, The University of Alabama at Birmingham, Birmingham, Alabama, USA

${ }^{6}$ East Azerbaijan Provincial Health Centre, Tabriz University of Medical Sciences, Tabriz, Iran

Acknowledgements The authors thank Eastern Azerbaijan province health center employees and district health managers for their contribution to data collection. This study was approved by Tabriz Health Services Management Research Center and School of Management and Medical Informatics, Tabriz University of Medical Sciences.

Contributors KG carried out proposal drafting, developed the study design, participated in data collection, performed the analyses and drafted the manuscript; JST carried out proposal drafting, participated in data collection and drafted the manuscript; MF participated in study design and coordination, and helped to draft the manuscript; SI participated in data collection, performed the analyses and drafted the manuscript; $A G$ and $\mathrm{HJ}$ developed the study design, provided coordination and helped draft the manuscript. All authors read and approved the final manuscript.

Funding This study was supported by the School of Management and Medical Informatics of Tabriz University of Medical Sciences, Tabriz Health Services Management Research Centre and Health Deputy of Tabriz University of Medical Sciences.

Competing interests None declared.

Patient consent Obtained.

Ethics approval The Tabriz University of Medical Sciences Research \& Ethics Committee (number: TBZMED.REC.1394.714) approved the design and procedure of this study.

Provenance and peer review Not commissioned; externally peer reviewed.

Data sharing statement The data sets supporting the conclusions of this article are included within the article.

Open Access This is an Open Access article distributed in accordance with the Creative Commons Attribution Non Commercial (CC BY-NC 4.0) license, which permits others to distribute, remix, adapt, build upon this work non-commercially, and license their derivative works on different terms, provided the original work is properly cited and the use is non-commercial. See: http://creativecommons.org/ licenses/by-nc/4.0/

(c) Article author(s) (or their employer(s) unless otherwise stated in the text of the article) 2018. All rights reserved. No commercial use is permitted unless otherwise expressly granted.

\section{REFERENCES}

1. Bhutta ZA, Chopra M, Axelson H, et al. Countdown to 2015 decade report (2000-10): taking stock of maternal, newborn, and child survival. Lancet 2010;375:2032-44.

2. Salas E, DiazGranados D, Klein C, et al. Does team training improve team performance? A meta-analysis. Hum Factors 2008;50:903-33.

3. Saleh SS, Williams D, Balougan M. Evaluating the effectiveness of public health leadership training: the NEPHLI experience. Am J Public Health 2004;94:1245-9.

4. Muchekeza M, Chimusoro A, Gombe NT, et al. District health executives in Midlands province, Zimbabwe: are they performing as expected? BMC Health Serv Res 2012;12:335.

5. Fine J. Business schools and health care management training: a strategic perspective. Global Business School Network 2009:10-11.
6. Bonenberger M, Aikins M, Akweongo P, et al. What Do District Health Managers in Ghana Use Their Working Time for? A Case Study of Three Districts. PLoS One 2015;10:e0130633.

7. Asante A, Roberts G, Hall J. A review of health leadership and management capacity in the Solomon Islands. Pac Health Dialog 2012;18:166-7

8. Filerman G. Closing the management competence gap. Hum Resour Health 2003;1:1-3.

9. Seims LR, Alegre JC, Murei L, et al. Strengthening management and leadership practices to increase health-service delivery in Kenya: an evidence-based approach. Hum Resour Health 2012;10:25.

10. De Brouwere $\mathrm{V}$, Van Balen $\mathrm{H}$. Hands-on training in health district management. World Health Forum 1996;17:271-3.

11. Devadasan N, Elias M. Training Needs Assessment for District Health Managers. Bangalore: Institute of Public Health, 2008.

12. Prashanth NS, Marchal B, Devadasan N, et al. Advancing the application of systems thinking in health: a realist evaluation of a capacity building programme for district managers in Tumkur, India. Health Res Policy Syst 2014;12:42.

13. Segall M. District health systems in a neoliberal world: a review of five key policy areas. Int J Health Plann Manage 2003;18(Suppl 1):S5-S26.

14. Conn CP, Jenkins P, Touray SO. Strengthening health management: experience of district teams in The Gambia. Health Policy Plan 1996;11:64-71.

15. Pfeffermann G. Leadership and management quality: key factors in effective health systems. World Hosp Health Serv 2012;48:18-20.

16. Smidt A, Balandin S, Sigafoos J, et al. The Kirkpatrick model: a useful tool for evaluating training outcomes. J Intellect Dev Disabil 2009;34:266-74.

17. Tabrizi JS, Gholipour K, Farahbakhsh M, et al. Developing management capacity building package to district health manager in northwest of iran: a sequential mixed method study. J Pak Med Assoc 2016;66:1385-91.

18. Omar M, Gerein N, Tarin E, et al. Training evaluation: a case study of training Iranian health managers. Hum Resour Health 2009;7:20.

19. Díaz-Monsalve SJ. The impact of health-management training programs in Latin America on job performance. Cad Saude Publica 2004;20:1110-20.

20. Rogers A. Adults Learning for Development. New York: Cassell Educational Limited, 1992.

21. Rabbani F, Hashmani FN, Mukhi AA, et al. Hospital management training for the Eastern Mediterranean Region: time for a change? J Health Organ Manag 2015;29:965-72.

22. Egger D, Travis P, Dovlo D, et al. Strengthening management in low income countries; Making Health Systems Work Series. Working Paper 1. Geneva: World Health Organization, 2005.

23. Calhoun JG, Dollett L, Sinioris ME, et al. Development of an interprofessional competency model for healthcare leadership. $J$ Healthc Manag 2008;53:375-89.

24. McCarthy G, Fitzpatrick JJ. Development of a competency framework for nurse managers in Ireland. J Contin Educ Nurs 2009;40:346-50.

25. Stefl ME. Common competencies for all healthcare managers: the Healthcare Leadership Alliance model. J Healthc Manag 2008;53:360-73.

26. Beanland TJ, Lacey SD, Melkman DD, et al. Multimedia materials for education, training, and advocacy in international health: experiences with the Schistosomiasis Control Initiative CD-ROM. Mem Inst Oswaldo Cruz 2006;101:87-90.

27. Hands-on training in health district management. World health forum Geneva: World health organization, 1996.

28. Marquez L, Madubuike C. Country experience in organizing for quality: Zambia. QA Brief 1999;8:16.

29. Ziegler PB, Anyango H, Ziegler HD. The need for leadership and management training for community nurses: results of a Ugandan district health nurse survey. J Community Health Nurs 1997:14:119-30.

30. Waweru E, Opwora A, Toda M, et al. Are Health Facility Management Committees in Kenya ready to implement financial management tasks: findings from a nationally representative survey. BMC Health Serv Res 2013;13:404.

31. Pal DK, Toppo M, Gupta S, et al. A rapid appraisal of functioning of district programme management units under NRHM in Madhya Pradesh. Indian J Public Health 2009;53:151-6.

32. Rockers PC, Bärnighausen T. Interventions for hiring, retaining and training district health systems managers in low- and middle-income countries. Cochrane Database Syst Rev 2013:CD009035. 
Correction: Evaluation of the district health management

fellowship training programme: a case study in Iran

Gholipour K, Tabrizi JS, Farahbakhsh M, et al. Evaluation of the district health management fellowship training programme: a case study in Iran. BMJ Open 2018;8:e020603. doi: 10.1136/bmjopen-2017-020603

In this paper, reference $n .32$ should actually be:

Diaz-Monsalve S. Measuring the job performance of district health managers in Latin America. Ann Trop Med Parasitol 2003;97:299-311

Open Access This is an Open Access article distributed in accordance with the Creative Commons Attribution Non Commercial (CC BY-NC 4.0) license, which permits others to distribute, remix, adapt, build upon this work non-commercially, and license their derivative works on different terms, provided the original work is properly cited and the use is non-commercial. See: http://creativecommons.org/licenses/by-nc/4.0/

(c) Article author(s) (or their employer(s) unless otherwise stated in the text of the article) 2018. All rights reserved. No commercial use is permitted unless otherwise expressly granted.

BMJ Open 2018;8:e020603corr1. doi:10.1136/bmjopen-2017-020603corr1

A Check for updates 